\title{
Breast cancer incidence and early diagnosis in a family history risk and prevention clinic: 33 -year experience in 14,311 women
}

\author{
D. Gareth Evans ${ }^{1,2,3,4,5,8}$ - Sacha J. Howell ${ }^{4,5,6} \cdot$ Ashu Gandhi ${ }^{4,5,6} \cdot$ Elke M. van Veen ${ }^{2,3} \cdot$ Emma R. Woodward $^{1,3}$. \\ James Harvey ${ }^{4}$ Lester Barr ${ }^{4}$. Andrew Wallace ${ }^{2}$. Fiona Lalloo ${ }^{1}$. Mary Wilson ${ }^{4}$. Emma Hurley ${ }^{4}$. Yit Lim ${ }^{4}$. \\ Anthony J. Maxwell ${ }^{4,7}$. Elaine F. Harkness ${ }^{4,7}$. Anthony Howell ${ }^{4,5,6}$
}

Received: 12 February 2021 / Accepted: 13 July 2021 / Published online: 26 July 2021

(c) The Author(s) 2021

\begin{abstract}
Purpose Women at increased familial breast cancer risk have been offered screening starting at an earlier age and increased frequency than national Screening Programmes for over 30 years. There are limited data on longer-term largescale implementation of this approach on cancer diagnosis.

Methods Women at our institution at $\geq 17 \%$ lifetime breast cancer risk have been offered enhanced screening with annual mammography starting at age 35 or 5 -years younger than youngest affected relative, with upper age limit 50 for moderate and 60 for high-risk. Breast cancer pathology, stage and receptor status were assessed as well as survival from cancer diagnosis by Kaplan-Meier analysis.

Results Overall 14,311 women were seen and assessed for breast cancer risk, with 649 breast cancers occurring in 129,119 years follow up (post-prevalent annual incidence $=4.55 / 1000$ ). Of 323/394 invasive breast cancers occurring whilst on enhanced screening, most were lymph-node negative (72.9\%), T1 $(\leq 20 \mathrm{~mm}, 73.2 \%)$ and stage-1 $(61.4 \%), 126 / 394$ stage2-4 (32\%). 10-year breast cancer specific survival was 91.3\% (95\% CI 87.4-94.0) better than the 75.9\% (95\% CI 74.9-77.0) published for England in 2013-2017. As expected, survival was significantly better for women with screen detected cancers $(p<0.001)$. Ten-year survival was particularly good for those diagnosed $\leq 40$ at $93.8 \%(n=75 ; 95 \% \mathrm{CI}$ 84.2-97.6). Women with lobular breast cancers had worse 10-year survival at $85.9 \%$ (95\% CI 66.7-94.5). Breast cancer specific survival was good for 119 BRCAl/2 carriers with 20-year survival in BRCA1:91.2\% (95\% CI 77.8-96.6) and 83.8\% (62.6-93.5) for BRCA2.
\end{abstract}

Conclusions Targeted breast screening in women aged 30-60 years at increased familial risk is associated with good longterm survival that is substantially better than expected from population data.

Keywords $B R C A 1 \cdot B R C A 2 \cdot$ Breast cancer $\cdot$ Mammography $\cdot$ MRI $\cdot$ Screening

D. Gareth Evans

gareth.evans@mft.nhs.uk

1 Clinical Genetics Service, Manchester Centre for Genomic Medicine, Manchester University Hospitals NHS Foundation Trust, Manchester M13 9WL, UK

2 NW Genomic Laboratory Hub, Manchester Centre for Genomic Medicine, Manchester University Hospitals NHS Foundation Trust, Manchester M13 9WL, UK

3 Division of Evolution and Genomic Sciences, Faculty of Biology, Manchester Academic Health Science Centre, School of Biological Sciences, Medicine and Health, University of Manchester, Manchester, UK
4 Nightingale/Prevent Breast Cancer Centre, Wythenshawe Hospital, Manchester University NHS Foundation Trust, Manchester M23 9LT, UK

5 Manchester Breast Centre, Manchester Cancer Research Centre, The Christie Hospital, Manchester, UK

6 Division of Cancer Sciences, Faculty of Biology, Manchester Academic Health Science Centre, Medicine and Health, University of Manchester, Manchester, UK

7 Division of Informatics, Imaging \& Data Sciences, Faculty of Biology, School of Health Sciences, Medicine and Health, University of Manchester, Manchester M13 9PT, UK

8 Department of Genetic Medicine, Manchester Academic Health Sciences Centre (MAHSC), St Mary's Hospital, University of Manchester, Manchester M13 9WL, UK 


\section{Introduction}

Breast cancer is the most common cancer in females with approximately 54,500 women diagnosed annually in the UK (2016) and remains the leading cause of premature death in women aged 30-60 years [1].

A family history risk and prevention clinic (FHRPC) to improve early detection and preventive approaches was established in Manchester in 1987 [2] and was the forerunner to other similar clinics across the UK and in Europe. In-house [3] and national [4] management guidelines were developed and, in, the UK, endorsed by a series of guidelines by the National Institute for Health and Care Excellence (NICE 2004, 2006, 2013, 2017) [5] in response to clinical developments in risk assessment, genetic testing, screening, preventive therapy and risk reducing surgery.

Risk was initially assessed by a modification of the Claus tables [6] and later using the Tyrer-Cuzick [7] and BOADICEA models [8, 9]. The cloning of BRCAl and $B R C A 2$ in 1994-1995 [10,11] allowed predictive testing to identify which women had highest risk. Other high-penetrance breast cancer genes (lifetime-risk $>40 \%$ ) including TP53, PTEN, CDH1, STK11 and PALB2 have also been identified, $[12,13]$ as well as moderate-risk genes (lifetime-risk 20-30\%) ATM and CHEK2 [12].

Annual breast screening was introduced from age 35/40-50 for women at moderate lifetime risk (17-29\%), to age 60 for women at high risk $(30 \%+)[5,14-16]$ and MRI screening for those at very high risk [17-21]. Preventive therapy using tamoxifen and raloxifene was endorsed in the 2013 NICE guideline and anastrozole in 2017 [5, $21,22]$. The uptake of risk reducing breast surgery has gradually increased since its introduction in the UK in the early 1990's [2].

We report here the outcome of risk assessment and surveillance in 14,311 women referred to the Manchester FHPRC clinic between 1987 and 2020, in particular, to assess breast cancer incidence and case-fatality. Outcomes from such a largescale systematic approach utilising family history to enhance early detection rates by mammography screening has not yet been published to our knowledge.

\section{Materials and methods}

Women with a breast cancer family history, but unaffected personally, have been referred to the FHRPC at the Nightingale Centre Withington/Wythenshawe hospital since 1987. Their lifetime and residual risk of breast cancer has been assessed using questionnaire information on family history and standard risk factors using Claus tables and the
Tyrer-Cuzick programme [2, 7-9, 23, 24]. Women were classified as being high-risk (lifetime-risk $\geq 30 \%$ ), moderate-risk (lifetime-risk 17-29\%) or average/population risk (lifetime-risk $<17 \%$ ). Average-risk women were returned to primary care with reassurance and information on breast awareness and advised to start or continue screening from age 50. Moderate-risk and high-risk women were offered 'enhanced' surveillance [annual mammography and clinical breast examination (CBE)] starting at 35 years or 5 years younger than youngest affected relative (earliest age 30) with upper age limit 50 for moderate and 60 for high-risk. For high-risk women 'enhanced' surveillance continued at 12-18 monthly intervals from 50 to 60 years of age and started as young as age 30 (if BRCA1/2 or youngest relative $<35$ ). Women from families eligible for genetic testing (20\% BRCA1/2 likelihood 2004-2013, $10 \%$ likelihood $>2013$ ) were referred to Genetics. Women with proven $B R C A 1 / 2$ pathogenic variants (PVs) in the family were offered targeted testing for their familial variant. In contrast, unaffected women (without breast cancer) with a significant family history have only been offered a full BRCA1/2 screen since 2013 if an affected family member is unavailable and their a priori likelihood of a $B R C A 1 / 2 \mathrm{PV}$ is $\geq 10 \%$ [5]. BRCAl/2 pathogenic variant (PV) carriers have been offered annual MRI screening aged 30-50 years since 2006 [5]. However, some aged 35-50 years had MRI screening through the MARIBS trial from 1997 [17]. MRI and mammography were performed simultaneously in MARIBS and from 2014 in the National Screening programme, but were offered at 6-monthly alternating intervals between 2006 and 2013. Women with lifetime breast cancer risks $\geq 25 \%$, including $B R C A 1 / 2$ carriers, have had bilateral risk-reducing mastectomy (BRRM) discussions since 1994.

All FHRPC women seen from 1987 (including discharged) had assessment of vital (living/dead) and cancer status through the regional cancer registry and NHS systems in December-2012. Post 2012, deaths were notified to the clinic and breast cancer incidence was only assessed in those under ongoing surveillance. Women were censored for breast cancer incidence at: breast cancer diagnosis, BRRM, or death, if none, at last mammography (latest March 2020) or $01 / 12 / 2012$. Data on all breast cancers occurring in the screening programme including interval cancers occurring within 18-months of last mammogram were collated. This included pathology [invasive-ductal, lobular, ductal carcinoma in situ (CIS)], tumour size, lymph node status and oestrogen (ER)/progesterone and HER2 receptor status. HER2 testing was only available from 2005. ER+ HER2- and triple negative breast cancer (TNBC) groups include HER2 untested from $<2005$ as only $8.6 \%(6 / 70)$ and $7.3 \%$ $(10 / 137)$ of subsequent tests on invasive ductal cancer for $\mathrm{ER}-$ and ER+ respectively were also HER2+. Vital status 
was established on all breast cancer cases in April-2020 and causes of death confirmed from cancer records and death certification.

Breast cancers were defined as detected 'on programme' if they were diagnosed at screening episodes or within 18-months (interval cancers). Most women off programme were discharged to population breast screening on the 3 -yearly basis NHS breast screening programme aged 50 if moderate-risk and 60 if high-risk.

In addition to clinical BRCA1/2 (including CHEK2 c.1100delC) testing where indicated by likelihood of a $B R C A 1 / 2 \mathrm{PV}$, many families received testing of affected members through the Familial Breast Cancer Study (FBCS) and 1300 women (900 without breast cancer) consenting to the FHrisk study had testing of an extended panel of breast cancer genes through the BRIDGES study [25].

\section{Annual incidence rates}

Annual incidence rates were calculated excluding cancers at prevalent screen. The BRCA1 and BRCA2 PV carrier groups were eligible for follow up from testing date or date of clinic entry which ever was later. PV carriers tested after breast cancer diagnosis were included in the untested group if their family PV was known at diagnosis or to the appropriate risk category at clinic entry if their family PV was identified after diagnosis. Likewise, those testing negative for their family $B R C A 1 / 2 \mathrm{PV}$ were eligible from date of negative test and excluded from prospective analysis as a PV carrier if testing was after diagnosis. All other women were grouped with their original risk category including the small group of 31 women with other known moderate/high risk gene PVs at entry. The 16 patients with neurofibromatosis-1 (NF1) were classified as moderate risk [26].

\section{Statistical methods}

Breast cancer incidence was calculated excluding cancers detected on prevalence screen. Survival was assessed by Kaplan-Meier analysis and the log rank test to compare survival curves for categorical variables. Chi-squared tests were used to compare categorical variables. Differences in pathology variables in cancers on the screening programme used the high risk $B R C A 1 / 2$ negative group as the reference. $B R C A 1$ and $B R C A 2$ incidence and in those testing negative, was only assessed from date of mutation report. All $p$ values were based on two-sided tests and were considered statistically significant if $<0.05$. Analyses were performed using Stata version 14 .

The study was approved by the Central Manchester Research Ethics Committee (10/H1008/24).

\section{Results}

\section{Study population}

A total of 14,311 women without breast cancer, born between 1920 and 2003 (median: 1966), had their risk of breast cancer assessed (Fig. 1). Age at entry ranged from 16 to 81 years $($ median $=39.9 ; \mathrm{IQR}=33.9-46.9)$. Detailed study population characteristics are described (Table 1) according to final known genetic status. 736 women $(5.1 \%)$ have been identified as $B R C A$ PV carriers $(B R C A l=364$, $B R C A 2=372)$ Table $1.272(37.0 \%)$ of these were referred into the FHRPC as known PV carriers unaffected by breast cancer. The remainder were identified after clinic entry (Fig. 1). As such 298/14,311 (2.1\%) were identified as BRCA PV carriers with no known PV in the family at clinic entry. Overall BRCA testing in the individual woman or affected family member was completed in 4168 (29.1\%) clinic attenders. Of 649 women with breast cancer, 539 (83.1\%) had known BRCA status.

\section{Follow-up time}

There have been 129,119 women-years follow up with 649 breast cancers (588 post-prevalent), resulting in annual incidence of $4.55 / 1000$. This excluded 45 prevalent asymptomatic screen detected cancers $(0.31 \%)$ and a further sixteen women who developed symptomatic breast cancer between referral and clinic attendance. Therefore, there were 61 total prevalent cancers $(0.43 \%-61 / 14311)$. Within the enhanced screening programme there were 63,972 years follow up, 349 (2.4\%) women developed breast cancer following prevalence screen (incidence $=5.46 / 1000$ ). 455 women (455/14311-3.2\%) have undergone pre-symptomatic BRRM with seven occult breast cancers (1.5\%) diagnosed at surgery. The remaining 239 cancers occurred after clinic discharge making a total of 255 (including 16 pre-prevalent scan) off programme. Breast cancer incidence by risk group is shown in Table 2. Incidence post prevalence in BRCAI was $1.73 \%$ and in BRCA2 $1.55 \%$ annually from date of mutation report. The low rate in untested women reflects those at $25 \%$ risk and very young women prior to testing. Carriers of known PVs in other genes were included in the lifetime risk category known at entry due to low numbers.

\section{Cancers}

The age and known PV carrier status of the women with breast cancers are shown in Table 3. Cancer pathology on the FHRPC enhanced screening programme is shown in Table 4. BRCA1-related breast cancers were more likely 


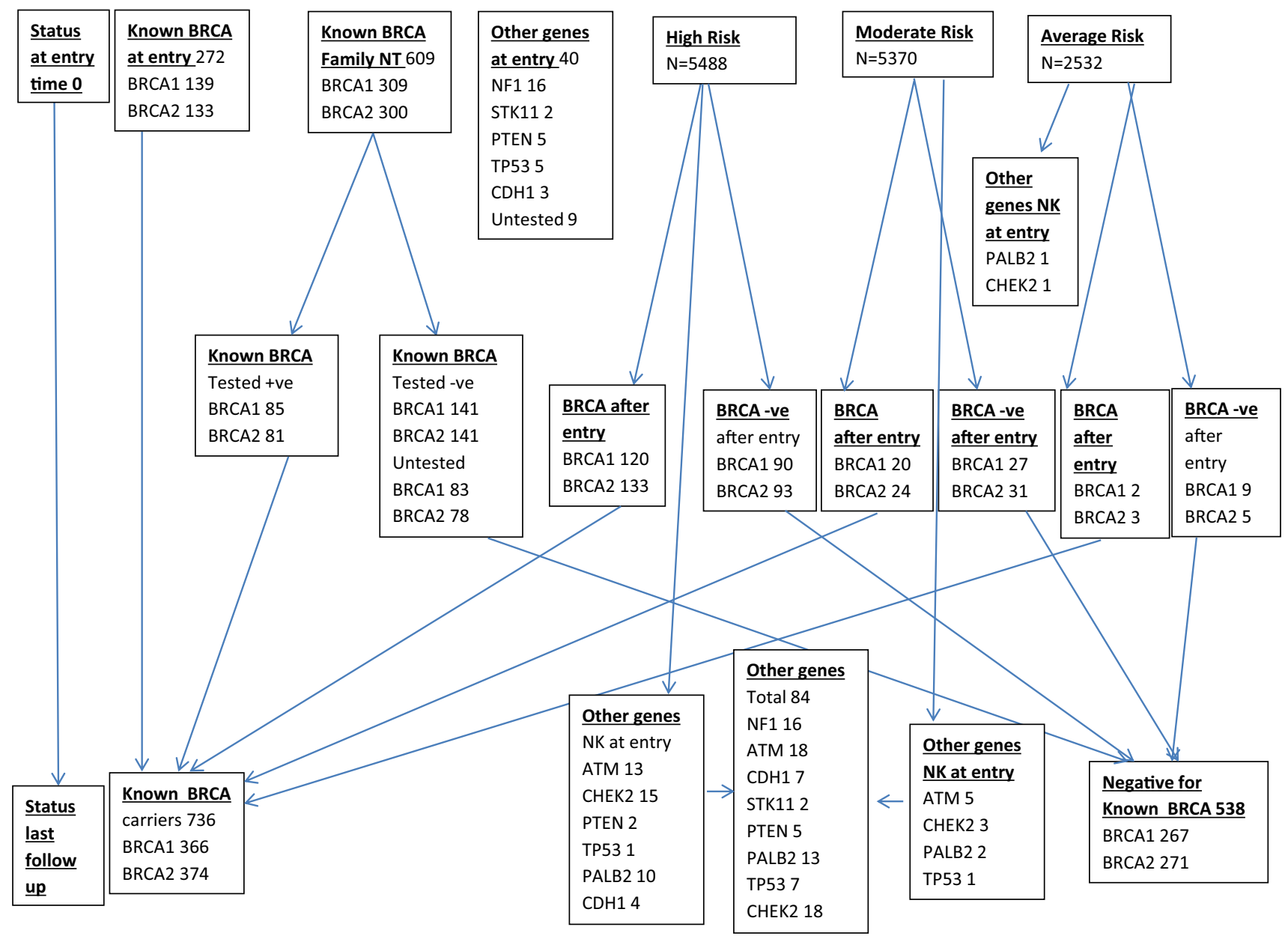

Fig. 1 Flow diagram of Gene status and risk at entry and later. $N T$ not tested, $N K$ not known, $B R C A$-ve negative for known BRCA PV in family, $B R C A+$ ve positive for known BRCA PV in family

grade 3 and oestrogen receptor negative (ER-) than cases in the high-risk BRCA negative cohort as expected $(p<0.0001$ for both). Tumours from women who tested BRCA PV negative in the high-risk cohort were more likely to be grade 1 than both BRCAI $(p<0.001)$ and BRCA2 $(p=0.04)$ tumours. Only $36 / 394(9 \%)$ women with cancers in the enhanced screening programme had no genetic testing compared with $84 / 255(32.9 \%)$ of those off programme. Of the cancers in the enhanced screening programme 70 (17.9\%) were CIS with a higher proportion seen on prevalent screen $(33.3 \%$ Supplementary Table S1). The majority of invasive cancers were lymph node negative (72.9\%), small ( $\leq 20 \mathrm{~mm}-73.2 \%$ ) and stage-1 (61.4\%). BRCA1/BRCA2 PV associated cancers were smaller overall with $75.0 \%$ and $85.4 \%$ being $\leq 20 \mathrm{~mm}$ respectively, potentially reflecting MRI screening in these groups. As screening was not universal $<35$ years we assessed the incidence of breast cancers aged 30-35 years in those with or without a relative diagnosed at $<35$ years. Of 1700 with a relative diagnosed $<35,740$ were seen aged $<35$ and $7(0.95 \%)$ diagnosed aged $30-35$. In contrast of 12,611 without such family history $15 / 3362(0.45 \%)$ seen $<35$ developed breast cancer aged 30-35 $(p=0.098)$.

\section{Clinical Breast Examination (CBE)}

Sixteen breast cancers (4\%) were initially identified as mammographically occult, but detected at the routine screen by CBE. Diagnoses were made after ultrasound guided biopsy with $9 / 16$ at stage- 1 and $11 \leq 20 \mathrm{~mm}$. 36 cancers were palpable at the mammogram appointment including 1/38 on the MRI program that was missed on previous MRI, but detected on alternating mammography $($ size $=29 \mathrm{~mm})$.

MRI screened Thirty-eight women were diagnosed with breast cancer on the MRI programme $(B R C A l=21$; $B R C A 2=16 ; T P 53=1)$. There were four occult cancers found at BRRM: three DCIS $2-17 \mathrm{~mm}$ and an invasive $13 \mathrm{~mm}$ tumor. Of those detected by screening 31/34 (91\%) were $\leq 20 \mathrm{~mm}($ DCIS $=1)$ and $18 / 34(53 \%) \leq 10 \mathrm{~mm}$. Overall $7 / 38(18.4 \%)$ were DCIS, with only two stage-2 can- 
Table 1 Risk and gene PV status of all 14,311 women assessed at the Manchester FHRPC

\begin{tabular}{|c|c|c|c|c|c|c|c|c|c|}
\hline Gene/risk & Number & Breast cancer & $\% \mathrm{BC}(\%)$ & RRM & $\%$ RRM (\%) & Deceased & $\begin{array}{l}\text { Median } \\
\text { age at } \\
\text { entry }\end{array}$ & IQR & $\begin{array}{l}\text { Proportion } \\
\text { of clinic (\%) }\end{array}$ \\
\hline$B R C A 1$ & 366 & 77 & 21.04 & 121 & 33.24 & 20 & 35.7 & $31.0-42.5$ & 2.54 \\
\hline BRCA2 & 374 & 78 & 20.86 & 101 & 27.15 & 19 & 36.9 & $31.9-45.0$ & 2.60 \\
\hline$A T M$ & 18 & 9 & 50.0 & 0 & 0.00 & 0 & 41.7 & $37.9-45.0$ & 0.11 \\
\hline $\mathrm{CDH1}$ & 7 & 2 & 28.57 & 4 & 57.14 & 0 & 35.1 & $33.9-46.8$ & 0.05 \\
\hline STK11 & 2 & 0 & 0.00 & 0 & 0.00 & 0 & 38.4 & & 0.01 \\
\hline PTEN & 5 & 2 & 40.00 & 1 & 20.00 & 1 & 35.8 & $35.3-36.5$ & 0.03 \\
\hline$P A L B 2$ & 13 & 6 & 46.15 & 0 & 0.00 & 0 & 38.0 & $34.3-42.0$ & 0.09 \\
\hline CHEK2 & 18 & 7 & 38.89 & 2 & 11.11 & 0 & 39.5 & $30.7-44.9$ & 0.13 \\
\hline$N F 1$ & 16 & 0 & 0.00 & 0 & 0.00 & 0 & 41.8 & $40.9-44.2$ & 0.11 \\
\hline TP53 & 7 & 3 & 42.86 & 0 & 0.00 & 1 & 32.1 & $27.5-34.8$ & 0.05 \\
\hline Negative for $B R C A 1$ in family & 267 & 5 & 1.87 & 7 & 2.62 & 0 & 37.5 & $32.1-44.4$ & 1.87 \\
\hline Negative for $B R C A 2$ in family & 271 & 10 & 3.69 & 6 & 2.21 & 3 & 39.4 & $32.5-45.4$ & 1.89 \\
\hline Untested for $B R C A 1$ in family & 115 & 2 & 1.74 & 1 & 0.87 & 0 & 34.5 & $31.5-40.9$ & 0.80 \\
\hline Untested for $B R C A 2$ in family & 135 & 1 & 0.74 & 2 & 1.48 & 1 & 38.3 & $31.7-46.1$ & 0.94 \\
\hline Negative for other actionable gene & 13 & 0 & 0.00 & 2 & 15.38 & 0 & 36.2 & $34.0-42.3$ & 0.09 \\
\hline Untested for other gene & 10 & 0 & 0.00 & 0 & 0.00 & 0 & 35.1 & $28.2-42.3$ & 0.07 \\
\hline \multicolumn{10}{|c|}{ No known high or moderate risk gene in family or individual including untested } \\
\hline High & 4939 & 217 & 4.39 & 171 & 3.46 & 69 & 39.7 & $34.7-47.0$ & 34.53 \\
\hline Moderate risk & 5234 & 181 & 3.46 & 37 & 0.71 & 73 & 40.3 & $34.2-46.5$ & 36.59 \\
\hline Average/population risk & 2501 & 48 & 1.92 & 0 & 0.00 & 82 & 41.5 & $33.9-34.7$ & 17.48 \\
\hline Total & 14311 & 649 & 4.51 & 455 & 3.18 & 269 & & & 100.00 \\
\hline
\end{tabular}

$R R M$ Risk reducing mastectomy, $I Q R$ Interquartile range, $B C$ Breast cancer

Table 2 Incidence rates for breast cancer by $B R C A 1 / 2$ and risk group

\begin{tabular}{llrllll}
\hline & Number & Follow up & BC & $\begin{array}{l}\text { BC annual } \\
\text { rate (\%) }\end{array}$ & Prevalent & \% Prevalent (\%) \\
\hline$B R C A 1^{\text {a }}$ & 309 & 1738.4 & 30 & 1.73 & 2 & 0.65 \\
$B R C A 2^{\text {a }}$ & 312 & 1811.3 & 28 & 1.55 & 2 & 0.64 \\
moderate in screening & 5293 & 28087.3 & 100 & 0.36 & 19 & 0.36 \\
High risk in screening & 5129 & 30392.3 & 192 & 0.63 & 29 & 0.57 \\
Moderate off screening & & 22091.6 & 83 & 0.38 & N/a & \\
High risk off screening & & 13298.5 & 81 & 0.61 & N/a & \\
Average & 2509 & 23924.8 & 49 & 0.20 & 1 & 0.04 \\
Negative for family BRCA2 & 218 & 1459.0 & 6 & 0.41 & 0 & \\
Negative for family BRCA1 & 194 & 1379.2 & 4 & 0.29 & 0 & \\
Untested for family BRCA1+ & 167 & 2390.3 & 7 & 0.29 & 3 & 1.80 \\
Untested for family BRCA2+ & 180 & 2546.9 & 8 & 0.31 & 5 & 2.78 \\
& 14311 & 129119.5 & 588 & & 61 & \\
\hline
\end{tabular}

${ }^{a}$ Includes 31 tested on research basis who have not had clinical testing including 7 BRCA1/2 with breast cancer + includes women tested after censor and follow up in women who later tested positive or negative but these numbers not included in total women

$B C$ breast cancer cers including the only case with lymph node involvement (size $=29 \mathrm{~mm}$-palpable $)$.
Cancer deaths Overall deaths were lower in women screened on the enhanced-programme (13.8\%) compared with off-programme (20.8\%) (Table 3), although off-programme women were older. Of the deaths with BRCA1/2 


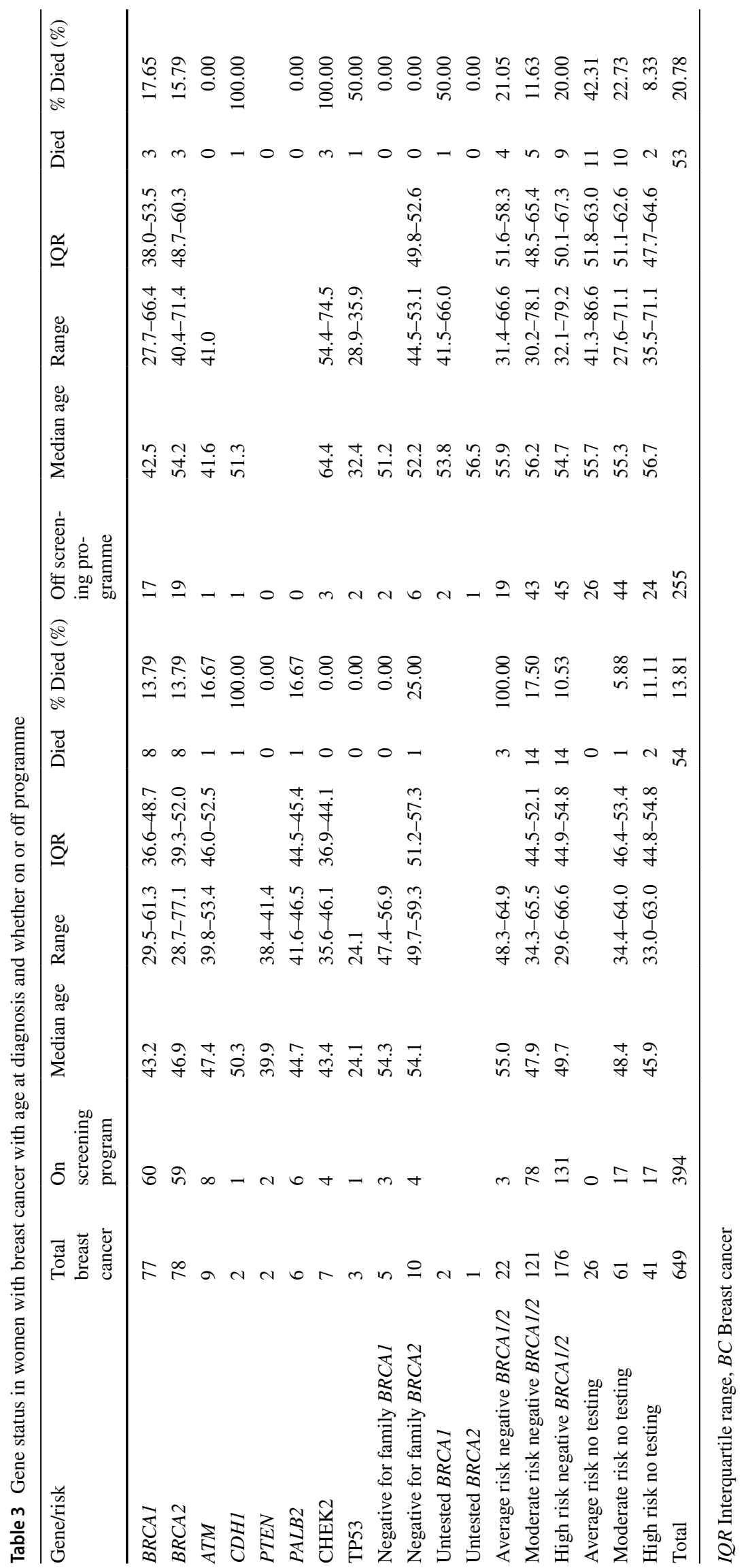




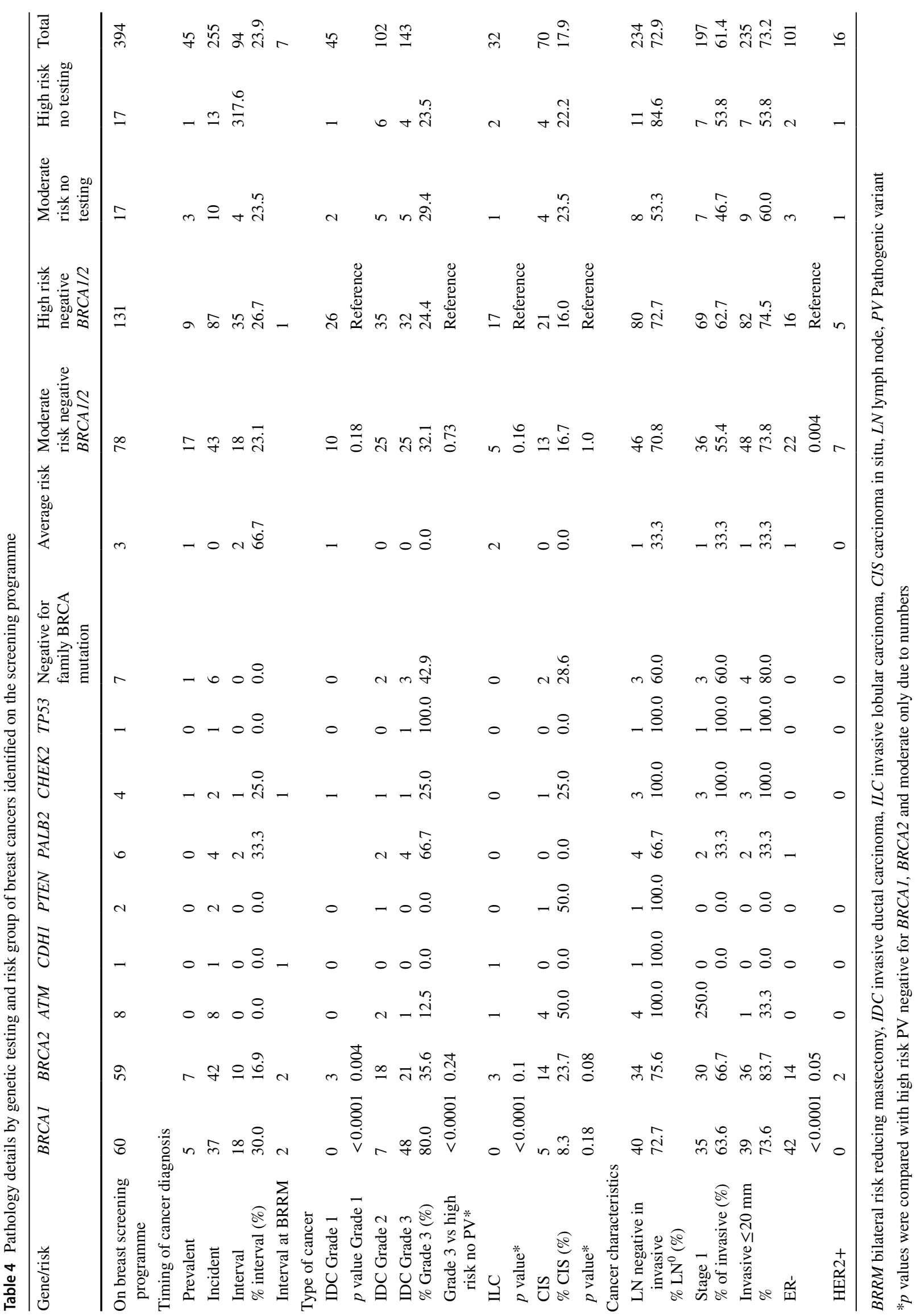


PVs, 7/16 were unrelated to breast cancer; BRCAl-4/8 [ovarian $(n=2)$, carcinosarcoma uterus $(n=1)$, pancreatic $(n=1)$ ], BRCA2-3/8 (ovarian, lung cancer, old-age). Only one each $B R C A 1$ and $B R C A 2$ deaths in carriers were breast cancer related in women on MRI screening (2/38). In total $34 / 54(63 \%)$ deaths in women with cancers detected in the enhanced screening programme were breast cancer related. There were two cancer deaths in women undergoing BRRM who had breast cancer (one breast, one pancreatic) $(0.44 \%)$ as well four non-cancer deaths for a total of $6 / 455(1.3 \%)$, compared to 274 total deaths in women not undergoing BRRM $(2 \%)$.
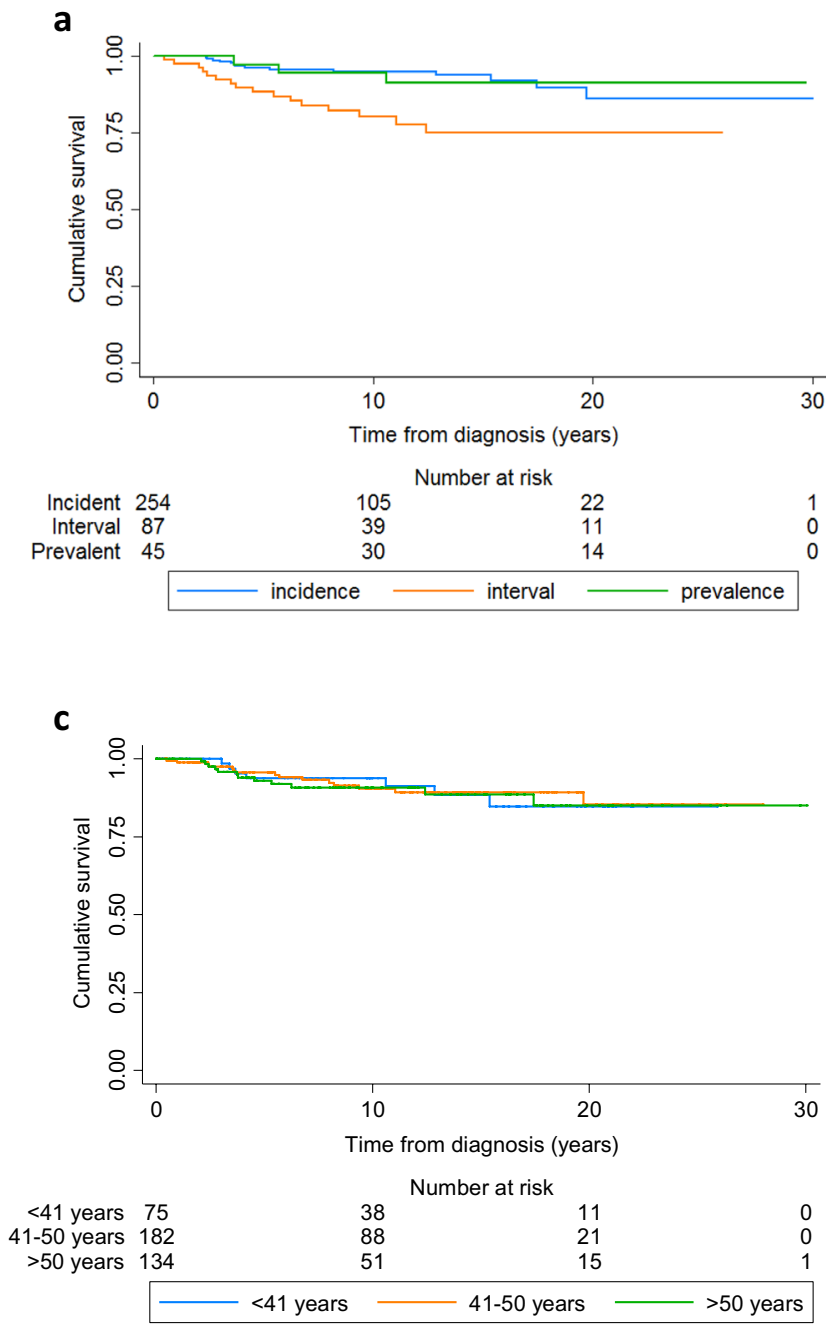

Fig. 2 a Survival by presentation (interval, incident, prevalent) breast cancer deaths. Incidence vs interval $(p<0.001)$, prevalence vs incidence $(p=0.052)$. b Survival by pathology type-breast cancer deaths. TNBC vs G1 $\mathrm{ER}+(p=0.04), \mathrm{G} 2 \mathrm{ER}+(p=0.03)$, CIS $(p=0.01)$; G1 ER+vs lobular $(p=0.015)$; G2 ER+vs lobular $(p=0.006)$; lobular vs CIS $(p<0.001)$; G3 ER+HER2- vs CIS
Cancer survival The 10-year breast cancer specific survival in women in the enhanced screening programme combined from prevalent, incident and interval cancers was $91.3 \%$ (95\% CI 87.4-94.0). Breast cancer deaths, as expected, were more frequent in women with symptomatic interval cancers (Supplementary Table S1, Fig. 2a). Incident screen detected 10-year survival was $91.9 \%$ (95\% CI $86.7-$ 95.1) vs interval $80.2 \%$ (95\% CI 68.6-87.9) $(p<0.001)$; prevalence screen survival $94.5 \%$ (95\% CI 79.8-98.6) vs incidence screen $(p=0.052)$. The pathologies with the highest proportion of breast cancer deaths were lobular [23.3\%, 10-year survival $=85.9 \%(95 \%$ CI 66.7-94.5) triple negative $[14.3 \%$; 10-year-survival $=83.5 \%(95 \% \mathrm{CI}$ 72.7-90.3)] and high-grade ER+HER2- cancers [13.0\%;

b

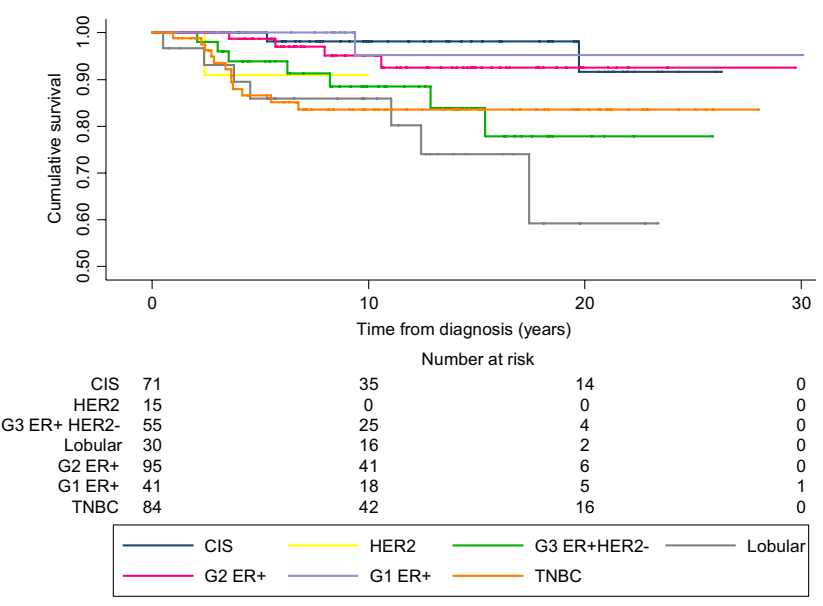

d

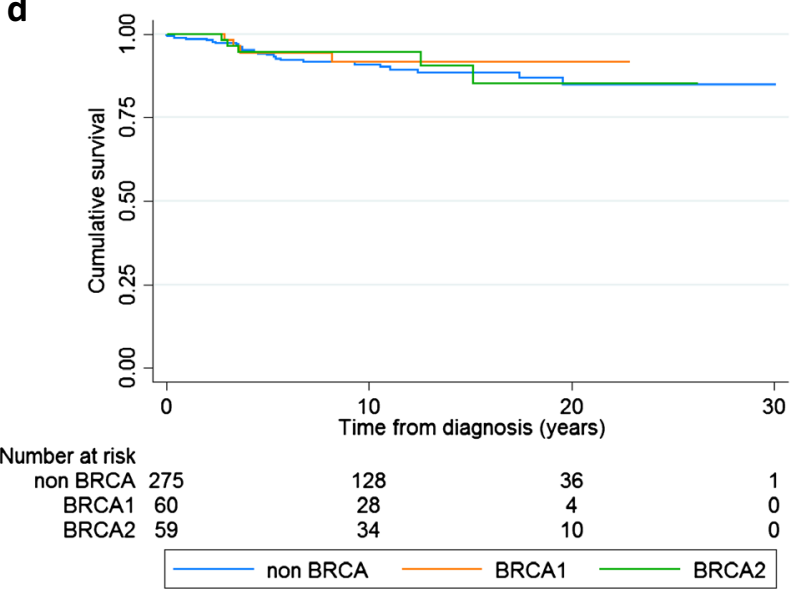

$(p=0.019)$. TNBC triple negative breast cancer, $C I S$ carcinoma in situ, $G$ grade, $E R$ estrogen receptor, $H E R 2$ human epidermal growth factor receptor 2. c Survival by age group-breast cancer deaths. d Kaplan-Meier breast cancer specific survival curves comparing $B R C A 1, B R C A 2$, and non-BRCA affected women 
10-year-survival $=88.5 \%$ (95\% CI 74.3-95.1) $]$ although numbers in each group were relatively small limiting statistical comparison. As expected, the lowest proportion of breast cancer specific deaths was noted in those with grade- 1 tumours $[2.4 \% ; 10$-year-survival $=95.5 \%(95 \%$ CI 70.7-99.3)] and CIS [2.8\%; 10-year-survival $=98.2 \%$ (95\% CI 87.6-99.7)], although breast cancer specific survival was also excellent in grade-2 ER + HER2- breast cancer $[10$-year-survival $=95.1 \%$ (95\% CI 85.3-98.4)]. Nearly all triple negative breast cancer deaths occurred in the first 5-years (Fig. 2b).

Although overall survival was worse in those diagnosed $>50$ years $(10$-year $=83.5 \% \leq 40$ years 10 -year $=93.5 \%, p=0.04 ; 41-50$ years 10 -year $=88.8 \%$, $p=0.025$ - Supplementary Figure S1), breast cancer specific survival was virtually identical for all age groups, with 10 -year $\leq 40$ years survival $93.8 \%$ (95\% CI 84.2-97.6-Supplementary Table S1; Fig. 2c). For the $\leq 40$ years group with invasive breast cancer $(n=58), 5,10$ and 20-year overall survival was $92.2 \%$ (80.5-97.0), 92.2\% (80.5-97.0) and $79.9 \%$ (59.9-90.6). Survival was not significantly different between BRCA1, BRCA2 and non-BRCA carriers on enhanced screening (Fig. 2d) with 20-year breast cancer specific survival particularly good in $60 \mathrm{BRCAl}$ carriers at $91.5 \%$ (78.5-96.8) compared to 59 BRCA2 at $85.1 \%$ (64.1-94.3) and 275 non-BRCA $84.7 \%$ (76.5-90.3). The $B R C A 2$ survival curve crossed over BRCA1 after 10 years. Only 51 BRCA carriers were aware of their status at breast cancer diagnosis. Kaplan-Meier curves comparing BRCA PV carriers who knew their status at diagnosis versus those who did not and BRCA carriers who had MRI versus those who only had mammography are shown in Supplementary Figures S2 and S3. Survival in the known carriers and MRI screened $(90.6 \%, 95 \%$ CI $80.3-95.7 \%)$ and $90.1 \%$ (95\% CI 62.6-97.7\%) 10-year survival respectively, but this was not significantly better than the controls who did not know their status (94.8\%; 95\% CI 68.0-93.2\%) and those not undergoing MRI (87.0\%: 95\% CI 80.6-94.8\%). We also carried out a time dependency analysis and this did not show any advantage to knowing the BRCA status (Supplementary Figure S4). Overall 20-year cumulative risk of breast cancer was 9.7\% (95\% CI 8.9-10.7\%—-Supplementary Figure S5).

Five and 10-year breast cancer specific survival in those with breast cancer detected on programme vs off programme screening was:5-year $94.1 \%$ (95\% CI 91.0-96.1) vs $94.3 \%$ (95\% CI 90.5-96.6) and 10-year 91.0\% (95\% CI 87.2-93.7) vs $90.4 \%$ (95\% CI 85.7-93.4) respectively. Overall 20-year survival in the cohort for all women for breast cancer specific survival was $98.8 \%$ (95\% CI 98.3-99.1\%) and for known BRCAl carriers $(n=365)=96.1 \%(95 \%$ CI $90.5-98.4 \%)$ and BRCA2 $(n=376)=91.5 \%$ (95\% CI 78.6-96.8\%). The latter should be regarded as an underestimate as not all women had undergone $B R C A 1 / 2$ testing.

\section{Discussion}

The current study is, to our knowledge, the largest study on systematic local approaches to breast cancer risk assessment and surveillance. In total 649 (4.5\%) of 14,311 women developed breast cancer with the majority [394 (62\%)] detected on enhanced screening. The majority of breast cancers were detected at stages $0 / 1$ (270/394-68.5\%) with only 94/394 (23.5\%) interval cancers, seven of which were asymptomatic at BRRM. There were expected breast cancer associations with $B R C A 1$ grade-3 ER- HER2 - [27], significantly more frequent than high-risk BRCA-negative group $(p<0.0001)$. Pure CIS was less frequent in BRCAI and more frequent in $B R C A 2$ [27]. There appears to be a stronger signal for low grade breast cancer (28\%) in those testing negative for PVs in high-risk genes suggesting a potential feature of yet to be discovered moderate/high-risk genes.

We have reported a mean annual rate of incident prospective breast cancers in BRCAl/2 PV carriers of $1.6 \%$ (1.55\% BRCA2, $1.73 \%$ BRCA1) [28], consistent with currently published $69-72 \%$ risks by age 80 years [29, 30] when extrapolated over a 50 -year risk period. This study also provides support for the current NICE recommended annual MRI screening surveillance strategy [5] as there was only one death in a BRCA2 carrier among MRI screened women. This continues to provide efficacy evidence for MRI as an alternative to BRRM [31], although $83 \%$ 20-year survival will still not convince many $B R C A 2$ carriers. Indeed, nearly half the deaths (44\%) in BRCA1/2 $\mathrm{PV}$ carriers with breast cancers were due to other cancers $(6 / 16)$ or old age (1/16). A study of 491 women with a germline BRCA mutation, who were annually screened with MRI and mammography for a median of 12.7 years found incidence breast cancer was $2 \%$ annually. There were four breast cancer-related deaths among 91 who developed breast cancer [32].

Breast cancer specific survival was excellent with 10-year survival rates of $91.3 \%$ (95\% CI 87.4-94.0) noticeably higher than current 10 -year breast cancer survival in England of all women presenting with primary breast cancer of 75.9\% (95\% CI 74.9-77.0; 2013-2017 data) [33]. Of particular note is that the 10 -year invasive breast cancer survival $\leq 40$ years of $92.2 \%$ (95\% CI 80.5-97.0) had lower 95\% CI above the UK population based POSH (Prospective-study-of-Outcomes-in-Sporadic-versus-Hereditarybreast-cancer) trial. This trial consisted of women presenting with primary breast cancer $\leq 40$ years between 2000 and 2008 [34]. The study found 10-year survival of $73.4 \%$ (67.4-78.5) for BRCA1/2 vs $70 \cdot 1 \%(67.7-72.3)$ for non BRCA breast cancer compared to the lower $95 \%$ CI of $86.9 \%$ in our population. Indeed, the Kaplan-Meier curves 
continued to drop towards $50 \%$ by 15 years in POSH [34] far below the 20-year survival from our study of $85.3 \%$ (77.1-90.7), and indeed the lower 95\% CI. Thus, even allowing 18-months lead-time [16] survival of women with invasive cancers $\leq 40$ who undergo annual screening is likely significantly better than unscreened women as suggested by the FH02 study [16].

As expected, women with interval breast cancers had higher mortality. Most presented within 12-months with known poorer survival [35]. Interestingly stage 2 or higher breast cancer was not different between incident and prevalent cases (27.6\% vs $26.7 \%$ ) among the screened population and this is reflected by similar survival rates. This is partly explained by the higher rates of DCIS (33\% vs $20.5 \%$ ). Although women presenting with triple negative cancers had relatively low 5-year survival, at 10-15 years this was no worse than for those with highgrade ER+HER2 - breast cancer. Interestingly, invasive lobular breast cancer, known to have higher interval cancer rates [29] presumably poorer mammographic sensitivity, was associated with the worst survival. Individuals with a higher risk of lobular cancer including those with $\mathrm{CDH} 1$ pathogenic variants, LCIS or lobular breast cancer family history should be considered for MRI breast screening. A small number of cancers (4\%) were detected only on CBE with a minority of the screen detected cancers also detected. We have previously highlighted this, but whether this is a cost-effective strategy despite the small size of most of these cancers will require further work [36]. We have also shown that use of a polygenic risk score from multiple Single Nucleotide Polymorphisms is accurate in reclassifying risk and will be a useful tool in targeting family history-based screening in future [14].

There are some limitations to the present study. Genetic testing was only carried out in a minority of the screened population although it was performed on the great majority of enhanced programme breast cancers (91\%) and assessment of incidence rates based on gene testing was not the primary study aim. Most women with breast cancers had panel testing, allowing extrapolation of likely frequencies of other common familial genes (ATM, CHEK2, PALB2). We do not have follow up for all women after December-2012, but were able to check vital status and cause of death for all women with breast cancer.

In conclusion, the present study has demonstrated good survival from family history based enhanced-screening approach over a 33-year period. Overall and breast cancer specific survival is very good and substantially better than would be expected from population statistics and especially $\leq 40$ years who would not otherwise qualify for screening. MRI screening is of benefit to BRCA1/2 carriers and could also be utilised in those at high risk of lobular cancer who are otherwise less well served by mammography.
Supplementary Information The online version contains supplementary material available at https://doi.org/10.1007/s10549-021-06333-1.

Acknowledgements DGE, EFH, SJH and AH are supported by the National Institute for Health Research (NIHR) BRC Manchester (Grant No. 1215-200074). This work was also supported by Prevent Breast Cancer. The authors have no relevant disclosures.

Data availability Raw data available on request.

\section{Declarations}

Conflict of interest DGE has received consultancy fees from Astrazeneca and Springworks. There are no other conflicts.

Open Access This article is licensed under a Creative Commons Attribution 4.0 International License, which permits use, sharing, adaptation, distribution and reproduction in any medium or format, as long as you give appropriate credit to the original author(s) and the source, provide a link to the Creative Commons licence, and indicate if changes were made. The images or other third party material in this article are included in the article's Creative Commons licence, unless indicated otherwise in a credit line to the material. If material is not included in the article's Creative Commons licence and your intended use is not permitted by statutory regulation or exceeds the permitted use, you will need to obtain permission directly from the copyright holder. To view a copy of this licence, visit http://creativecommons.org/licenses/by/4.0/.

\section{References}

1. https://www.cancerresearchuk.org/about-cancer/breast-cancer/ risks-causes/risk-factors. Accessed 19 April 2020

2. Howell A, Gandhi A, Howell S, Wilson M, Maxwell A, Astley S, Harvie M, Pegington M, Barr L, Baildam A, Harkness E, Hopwood P, Wisely J, Wilding A, Greenhalgh R, Affen J, Maurice A, Cole S, Wiseman J, Lalloo F, French DP, Evans DG (2020) Long-term evaluation of women referred to a breast cancer family history clinic (Manchester UK 1987-2020). Cancers (Basel) 12(12):3697. https://doi.org/10.3390/cancers12123697

3. Evans DG, Fentiman IS, McPherson K, Asbury D, Ponder BA, Howell A (1994) Familial breast cancer. BMJ 308(6922):183-187

4. Eccles DM, Evans DGR, Mackay J (2000) Guidelines for a genetic risk based approach to advising women with a family history of breast cancer. J Med Genet 37:203-209

5. McIntosh A, Shaw C, Evans G et al (2004) Clinical guidelines and evidence review for the classification and care of women at risk of familial breast cancer, London: National Collaborating Centre for Primary Care/University of Sheffield. NICE guideline CG164. https://www.nice.org.uk/Guidance/CG164. Accessed 2 Feb 2021

6. Claus EB, Risch N, Thompson WD (1994) Autosomal dominant inheritance of early-onset breast cancer. Implications for risk prediction. Cancer 73(3):643-651

7. Tyrer J, Duffy SW, Cuzick J (2004) A breast cancer prediction model incorporating familial and personal risk factors. Stat Med 23(7):1111-1130. https://doi.org/10.1002/sim.1668

8. Antoniou AC, Pharoah PP, Smith P, Easton DF (2004) The BOADICEA model of genetic susceptibility to breast and ovarian cancer. Br J Cancer 91(8):1580-1590. https://doi.org/10.1038/sj.bjc. 6602175 
9. Amir E, Evans DG, Shenton A et al (2003) Evaluation of breast cancer risk assessment packages in the family history evaluation and screening programme. J Med Genet 40(11):807-814

10. Miki Y, Swensen J, Shattuck-Eidens D et al (1994) A strong candidate for the breast and ovarian cancer susceptibility gene BRCA1. Science 266(5182):66-71

11. Wooster R, Bignell G, Lancaster J et al (1995) Identification of the breast cancer susceptibility gene BRCA2. Nature 378(6559):789-792

12. Easton DF, Pharoah PD, Antoniou AC et al (2015) Gene-panel sequencing and the prediction of breast-cancer risk. N Engl J Med 372(23):2243-2257

13. Yang X, Leslie G, Doroszuk A et al (2019) Cancer risks associated with germline PALB2 pathogenic variants: an international study of 524 families. J Clin Oncol. https://doi.org/10.1200/JCO. 19.01907

14. Maurice A, Evans DG, Affen J, Greenhalgh R, Duffy SW, Howell A (2012) Surveillance of women at increased risk of breast cancer using mammography and clinical breast examination: further evidence of benefit. Int J Cancer 131(2):417-425

15. FH01 collaborative teams (2010) Mammographic surveillance in women younger than 50 years who have a family history of breast cancer: tumour characteristics and projected effect on mortality in the prospective, single-arm, FH01 study. Lancet Oncol 11(12):1127-1134

16. Evans DG, Thomas S, Caunt J et al (2019) Final results of the prospective FH02 mammographic surveillance study of women aged 35-39 at increased familial risk of breast cancer. EClinicalMedicine 7:39-46

17. Leach MO, Boggis CR, Dixon AK et al (2005) Screening with magnetic resonance imaging and mammography of a UK population at high familial risk of breast cancer: a prospective multicentre cohort study (MARIBS). Lancet 365(9473):1769-1778

18. Kuhl CK, Schrading S, Leutner CC et al (2005) Mammography, breast ultrasound, and magnetic resonance imaging for surveillance of women at high familial risk for breast cancer. J Clin Oncol 23(33):8469-8476

19. Kriege M, Brekelmans CT, Boetes C, Magnetic Resonance Imaging Screening Study Group et al (2004) Efficacy of MRI and mammography for breast-cancer screening in women with a familial or genetic predisposition. N Engl J Med 351(5):427-437

20. Warner E, Plewes DB, Hill KA, Causer PA, Zubovits JT, Jong RA, Cutrara MR, DeBoer G, Yaffe MJ, Messner SJ, Meschino WS, Piron CA, Narod SA (2004) Surveillance of BRCA1 and BRCA2 mutation carriers with magnetic resonance imaging, ultrasound, mammography, and clinical breast examination. JAMA 292(11):1317-1325

21. Cuzick J, Sestak I, Cawthorn S, Hamed H, Holli K, Howell A, Forbes JF, IBIS-I Investigators (2015) Tamoxifen for prevention of breast cancer: extended long-term follow-up of the IBIS-I breast cancer prevention trial. Lancet Oncol 16(1):67-75. https://doi.org/ 10.1016/S1470-2045(14)71171-4

22. Cuzick J, Sestak I, Forbes JF, Dowsett M, Cawthorn S, Mansel RE, Loibl S, Bonanni B, Evans DG, Howell A, IBIS-II investigators (2020) Use of anastrozole for breast cancer prevention (IBIS-II): long-term results of a randomised controlled trial. Lancet 395(10218):117-122. https://doi.org/10.1016/S0140-6736(19) 32955-1
23. Evans DG, Astley S, Stavrinos P et al (2016) Improvement in risk prediction, early detection and prevention of breast cancer in the NHS breast screening programme and family history clinics: a dual cohort study. NIHR Journals Library, Southampton

24. Evans DG, Ingham S, Dawe S et al (2014) Breast cancer risk assessment in 8,824 women attending a family history evaluation and screening programme. Fam Cancer 13(2):189-196

25. Dorling L, Carvalho S, Allen J et al (2021) Breast cancer risk genes: association analysis of rare coding variants in 34 genes in 60,466 cases and 53,461 controls. N Engl J Med 384(5):428-439

26. Howell SJ, Hockenhull K, Salih Z, Evans DG (2017) Increased risk of breast cancer in neurofibromatosis type 1: current insights. Breast Cancer (Dove Med Press) 21(9):531-553

27. Lakhani SR, Van De Vijver MJ, Jacquemier J et al (2002) The pathology of familial breast cancer: predictive value of immunohistochemical markers estrogen receptor, progesterone receptor, HER-2, and p53 in patients with mutations in BRCA1 and BRCA2. J Clin Oncol 20(9):2310-2318

28. Kuchenbaecker KB, Hopper JL, Barnes DR et al (2017) Risks of breast, ovarian, and contralateral breast cancer for BRCA1 and BRCA2 mutation carriers. JAMA 317(23):2402-2416. https://doi. org/10.1001/jama.2017.7112

29. Evans DG, Harkness E, Lalloo F, Howell A (2014) Long-term prospective clinical follow-up after BRCA1/2 presymptomatic testing: BRCA2 risks higher than in adjusted retrospective studies. J Med Genet 51(9):573-580

30. Mavaddat N, Peock S, Frost D et al (2013) Cancer risks for BRCA1 and BRCA2 mutation carriers: results from prospective analysis of EMBRACE. J Natl Cancer Inst 105(11):812-822

31. Evans DG, Kesavan N, Lim Y, Gadde S et al (2014) MRI breast screening in high-risk women: cancer detection and survival analysis. Breast Cancer Res Treat 145(3):663-672

32. Warner E, Zhu S, Plewes DB et al (2020) Breast cancer mortality among women with a BRCA1 or BRCA 2 mutation in a magnetic resonance imaging plus mammography screening program. Cancers (Basel) 12(11):3479

33. https://www.cancerresearchuk.org/health-professional/cancerstatistics/statistics-by-cancer-type/breast-cancer/survival\#headi ng-Zero. Accessed 20 July 2020

34. Copson ER, Maishman TC, Tapper WJ et al (2018) Germline BRCA mutation and outcome in young-onset breast cancer (POSH): a prospective cohort study. Lancet Oncol 19(2):169-180

35. Irvin VL, Zhang Z, Simon MS et al (2020) Comparison of mortality among participants of women's health initiative trials with screening-detected breast cancers vs interval breast cancers. JAMA Netw Open 3(6):e207227

36. Evans DG, Brentnall A, Byers H, Harkness E, Stavrinos P, Howell A, Newman WG, Cuzick J, FH-risk study Group (2017) The impact of a panel of 18 SNPs on breast cancer risk in women attending a UK familial screening clinic: a case-control study. J Med Genet 54(2):111-113

Publisher's Note Springer Nature remains neutral with regard to jurisdictional claims in published maps and institutional affiliations. 